\title{
Erratum to: Application of confocal laser scanning microscopy (CLSM) to visualize the effect of porous media wettability on unsaturated pore water configuration
}

Gawan Jacob Hilma Muehl • Joerg Ruehlmann •

Marc-Oliver Goebel • Joerg Bachmann

Published online: 6 September 2011

(C) Springer-Verlag 2011

Erratum to: J Soils Sediments

DOI 10.1007/s11368-011-0395-7

Unfortunately the surnames of the first and second author were written incorrectly. The correct names in full are Gawan Jacob Hilma Muehl and Joerg Ruehlmann

The online version of the original article can be found at http://dx.doi. org/10.1007/s11368-011-0395-7.

G. J. H. Muehl $(\bowtie) \cdot$ J. Ruehlmann

Institute of Vegetable and Ornamental Crops Großbeeren/Erfurt,

Theodor-Echtermeyer-Weg 1,

14979 Großbeeren, Germany

e-mail: muehl@igzev.de

M.-O. Goebel $\cdot$ J. Bachmann

Institute of Soil Science, Leibniz University of Hannover,

Herrenhäuser Str. 2,

30419 Hannover, Germany 